\title{
A Coupled Mathematical Model of Microsegregation and Inclusion Precipitation during Solidification of Silicon Steel
}

\author{
Zhongzhu LIU, Jun WEI ${ }^{1)}$ and Kaike CAI ${ }^{21}$ \\ Formerly graduate Student, Institute of Steelmaking, Metallurgical Engineering School, University of Science and Technology \\ Beijing, Beijing 100083 China. Now at Metallurgical Processing Group, Steel Research Center, National Institute for Materials \\ Science, Sengen, Tsukuba, Ibaraki 305-0047 Japan. E-mail: LIU.Zhongzhu@nims.go.jp \\ 1) Graduate Student, Institute of Steelmaking, Metallurgical Engineering School, University of Science and Technology Beijing, \\ Beijing 100083 China. $\quad 2$ 2) Institute of Steelmaking, Metallurgical Engineering School, University of Science and \\ Technology Beijing, Beijing 100083 China. E-mail: kaikecai@metall.ustb.edu.cn
}

(Received on January 21, 2002; accepted in final form on May 31, 2002)

\begin{abstract}
A coupled mathematical model of microsegregation and inclusion precipitation during solidification is established. The model can be used to calculate the kind of precipitated inclusion, the amount of inclusion precipitation and the growth of inclusion during solidification. The calculation by this model shows that the segregation degree of solute elements is suppressed greatly due to the precipitation of inclusions during solidification. A non-coupled model will overestimate the segregation degree and the amount of inclusion precipitation and even give a wrong prediction for the kind of the inclusions. In this paper, the effects of cooling rate on the precipitation and growth of oxides are also discussed.
\end{abstract}

KEY WORDS: solidification; microsegregation; inclusion precipitation; mathematical model; oxide; sulfide.

\section{Introduction}

The non-metallic inclusions in steel mainly precipitate during deoxidation and solidification, and steel properties are strongly effected by them. Many studies ${ }^{1-3)}$ were reported about the precipitation, cohesion and remove of inclusions during deoxidation. Recently, due to the development of Oxide Metallurgy Technology, some projects ${ }^{4-6}$ have been developed to study the behavior of inclusion precipitation during solidification. At the same time, the fine inclusions, which mostly precipitate during solidification, are the most harmful inclusions to magnetic properties of silicon steel.

Many experiments and mathematical models ${ }^{7-10)}$ of microsegregation and/or inclusion precipitation were reported. But in these models, the microsegregation of solute elements and inclusion precipitation were calculated separately, which could overestimate the segregation degree and the amount of precipitated inclusion.

In this paper, a mathematical model of inclusion precipitation during solidification is presented based on $\mathrm{Y}$. Ueshima's microsegregation model. ${ }^{10-12)}$ The coupled calculation of microsegregation of solute elements and inclusion precipitation is carried out and the precipitation of oxides and sulfides calculated simultaneously in this model. The microsegregation degrees of solute elements are compared with coupled and non-coupled model. The effects of cooling rate on the precipitation and growth of oxide are also discussed in this paper. The calculated results are more suited to actual situation and agree well with the experiment results and data reported.

\section{Mathematical Model}

\subsection{Previous Work}

The classical treatment of inclusion precipitation during solidification is the juxtaposition of microsegregation equations with a liquid metal-inclusions equilibrium model. But in the reported studies the simultaneous phenomenon, solute microsegregation/reditribution and inclusion precipitation, were calculated separately or successively.

In these studies, the concentrations of solute elements (for example, $C_{\mathrm{Mn}}^{\mathrm{L}}$ and $C_{\mathrm{S}}^{\mathrm{L}}$ ) in liquid steel were calculated by microsegregation model at a special solid fraction $f_{\mathrm{S}}$ during solidification. When the product of manganese and sulfur concentrations exceeds the equilibrium solubility of $\mathrm{MnS}$ in liquid steel, MnS precipitates in agreement with the solubility. The amount of manganese and sulfur consumed due to $\mathrm{MnS}$ precipitation $\left(\Delta C_{\mathrm{Mn}}^{\mathrm{L}}, \Delta C_{\mathrm{S}}^{\mathrm{L}}\right)$ is calculated as follows.

$$
\begin{gathered}
\left(C_{\mathrm{Mn}}^{\mathrm{L}}-\Delta C_{\mathrm{Mn}}^{\mathrm{L}}\right)\left(C_{\mathrm{S}}^{\mathrm{L}}-\Delta C_{\mathrm{S}}^{\mathrm{L}}\right)=K_{\mathrm{MnS}}^{\mathrm{L}} \\
\Delta C_{\mathrm{Mn}}^{\mathrm{L}} / \Delta C_{\mathrm{S}}^{\mathrm{L}}=M_{\mathrm{Mn}} / M_{\mathrm{S}} \\
\left(C_{\mathrm{Mn}}^{\mathrm{L}}\right)^{\prime}=C_{\mathrm{Mn}}^{\mathrm{L}}-\Delta C_{\mathrm{Mn}}^{\mathrm{L}} \\
\left(C_{\mathrm{S}}^{\mathrm{L}}\right)^{\prime}=C_{\mathrm{S}}^{\mathrm{L}}-\Delta C_{\mathrm{S}}^{\mathrm{L}}
\end{gathered}
$$

Where $M_{\mathrm{Mn}}$ and $M_{\mathrm{S}}$ is the atomic weight of $\mathrm{Mn}$ and $\mathrm{S}$ respectively, $\left(C_{\mathrm{Mn}}^{\mathrm{L}}\right)^{\prime}$ and $\left(C_{\mathrm{S}}^{\mathrm{L}}\right)^{\prime}$ is the concentration of $\mathrm{Mn}$ and $\mathrm{S}$ in liquid steel after $\mathrm{MnS}$ precipitation respectively.

But some theoretical problems still remain. The simultaneous phenomenon are divided into two steps artificially in these studies: first, distribution of solute elements; second, 
inclusion precipitation. Calculation like these studies may overestimate the microsegregation degree of solute elements and the amount of precipitated inclusion and even give a wrong prediction for the kind of the precipitates.

\subsection{Microsegregation Model}

Y. Ueshima's model is used to calculate microsegregation of solute elements in molten and solid steels during solidification in this paper. The model takes into account a partial diffusion of alloying elements in solid phase and is based on the following assumptions:

(1) The geometry of the solid/liquid interface is plane.

(2) The calculation domain corresponds to the half secondary dendrite spacing as shown in Fig. 1.

(3) The temperature is uniform in the space element.

(4) The density of the liquid is equal to that of the solid.

(5) The composition of the liquid is uniform and at the solid/liquid interface the distribution of the solute elements between liquid and solid is described with their partition coefficient.

(6) A parabolic growth rate is assumed.

The above assumptions are reasonable over a wide range of casting conditions.

One-dimensional diffusion of seven elements ( $\mathrm{C}, \mathrm{Si}, \mathrm{Mn}$, $\mathrm{P}, \mathrm{S}, \mathrm{Al}$, and $\mathrm{O}$ ) is calculated by using different diffusion coefficients in solid phase.

The calculation is carried out by the direct finite difference method. Half area of the secondary dendrite spacing is divided into $\mathrm{N}$ nodes as shown in Fig. 2.

At time $t$,

in the solid phase $(1<i<m)$

$$
\frac{C_{i}^{t}-C_{i}^{t-\Delta t}}{\Delta t}=D \cdot \frac{C_{i+1}^{t-\Delta t}-2 \cdot C_{i}^{t-\Delta t}+C_{i-1}^{t-\Delta t}}{\Delta x^{2}} \ldots
$$

Where $C_{i}^{t}$ is the concentration of solute elements in weight percent in nodal $i$ at time $t, D$ is diffusion coefficient in solid phase.

at the node $i=1$

$$
\frac{C_{i}^{t}-C_{i}^{t-\Delta t}}{\Delta t}=D \cdot \frac{C_{i+1}^{t-\Delta t}-C_{i}^{t-\Delta t}}{\Delta x^{2}}
$$

at the solid/liquid interface $(i=m)$

$$
C_{m}^{t}=C_{\mathrm{L}}^{t} \cdot k^{\delta / \mathrm{L}}
$$

Where $k^{\delta / \mathrm{L}}$ is the partition coefficient of solute elements be-

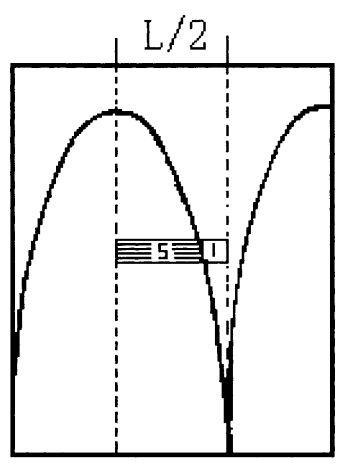

Fig. 1. A schematic diagram of the calculation domain. tween liquid and solid ( $\delta$ phase).

The following equation can be derived from a mass balance.

$$
N \cdot C_{\mathrm{L}}^{0}=\sum_{i=1}^{m} C_{i}^{t}+(N-m) \cdot C_{\mathrm{L}}^{t}
$$

Where $C_{\mathrm{L}}^{0}$ is the initial solute concentration.

Combining Eqs. (1)-(4), the following equations can be obtained.

$$
\begin{gathered}
C_{\mathrm{L}}^{t}=\frac{N \cdot C_{\mathrm{L}}^{0}-\sum_{i=1}^{m-1} C_{i}^{t-\Delta t}+F^{\prime} \cdot C_{m-1}^{t-\Delta t}}{(N-m)+\left(1+F^{\prime}\right) \cdot k^{\delta \mathrm{L}}} \\
C_{m}^{t}=\frac{N \cdot C_{\mathrm{L}}^{0}-\sum_{i=1}^{m-1} C_{i}^{t-\Delta t}+F^{\prime} \cdot C_{m-1}^{t-\Delta t}}{(N-m) / k^{\delta \mathrm{L}}+1+F^{\prime}}
\end{gathered}
$$

where,

$$
F^{\prime}=\frac{D \cdot \Delta t}{\Delta x^{2}}=\frac{4 \cdot D \cdot t_{\mathrm{s}}}{L^{2}} \cdot N^{2} \cdot\left(\left(f_{\mathrm{s}}^{t}\right)^{2}-\left(f_{\mathrm{s}}^{t-\Delta t}\right)^{2}\right)
$$

and $f_{\mathrm{s}}^{t}$ is the solid fraction at time $t, L$ is the secondary dendrite spacing, $t_{\mathrm{s}}$ is the local solidification time.

The studied silicon steel in this paper has a composition of $0.04 \% \mathrm{C}, 3.0 \% \mathrm{Si}, 0.058 \% \mathrm{Mn}, 0.01 \% \mathrm{P}, 0.022 \% \mathrm{~S}$, $0.0022 \% \mathrm{Al}$ and $0.0010 \% \mathrm{O}$. According to $\mathrm{Fe}-\mathrm{Si}$ phase diagram, there is no $\delta / \gamma$ transformation from liquid to solid if the composition of carbon is less than $0.1 \%$ in silicon steel. The liquidus and solidus temperature can be calculated using the following relationships. ${ }^{12)}$

$$
\begin{aligned}
T_{\mathrm{L}}= & 1809-78 \cdot[\% \mathrm{C}]-7.6 \cdot[\% \mathrm{Si}]-4.9 \cdot[\% \mathrm{Mn}] \\
& -34.4 \cdot[\% \mathrm{P}]-38 \cdot[\% \mathrm{~S}]-3.6 \cdot[\% \mathrm{Al}] \\
T_{\mathrm{S}}= & 175 \cdot[\% \mathrm{C}]+20 \cdot[\% \mathrm{Si}]+30 \cdot[\% \mathrm{Mn}]+280 \cdot[\% \mathrm{P}] \\
& +575 \cdot[\% \mathrm{~S}]+7.5 \cdot[\% \mathrm{Al}]+160 \cdot[\% \mathrm{O}]
\end{aligned}
$$

The temperature at solid fraction $f_{\mathrm{S}}$ during solidification, $T$, is given as Eq. (7). ${ }^{9)}$

$$
T=T_{0}-\frac{T_{0}-T_{\mathrm{L}}}{1-f_{\mathrm{S}} \cdot \frac{T_{\mathrm{L}}-T_{\mathrm{S}}}{T_{0}-T_{\mathrm{S}}}}
$$

Where $T_{0}, T_{\mathrm{L}}$ and $T_{\mathrm{S}}$ represent the melting point of pure iron, liquidus and solidus temperature of steel studied respectively.

The secondary dendrite arm spacing can be calculated from Eq. (8). ${ }^{13)}$

$$
L=146(d T / d t)^{-0.39}, \quad \mu \mathrm{m}
$$

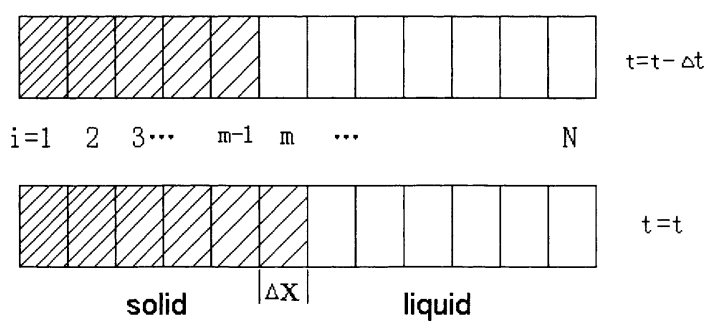

Fig. 2. Dividing of the calculation domain by nodal elements. 
Table 1. Equilibrium distribution coefficients and diffusion coefficients of solutes in iron.

\begin{tabular}{|c|c|c|c|}
\hline \multirow{2}{*}{ element } & \multicolumn{2}{|c|}{$\mathrm{D}_{\mathrm{s}}, \times 10^{-4} \mathrm{~m}^{2} / \mathrm{s}$} & \multirow{2}{*}{$k^{\delta / L}$} \\
\cline { 2 - 3 } & $\mathrm{D}_{\mathrm{o}}$ & $\mathrm{Q}, \mathrm{J} / \mathrm{mol}$ & \\
\hline $\mathrm{C}$ & 0.0127 & -81301 & 0.19 \\
\hline $\mathrm{Si}$ & 8.0 & -248710 & 0.77 \\
\hline $\mathrm{Mn}$ & 0.76 & -116935 & 0.77 \\
\hline $\mathrm{P}$ & 2.9 & -229900 & 0.23 \\
\hline $\mathrm{S}$ & 4.56 & -214434 & 0.05 \\
\hline $\mathrm{Al}$ & 5.9 & -241186 & 0.6 \\
\hline $\mathrm{O}$ & 0.0371 & -96349 & 0.03 \\
\hline
\end{tabular}

where $\quad D_{s}=D_{0}{ }^{*} \exp (\mathrm{Q} / \mathrm{RT}) \quad \mathrm{R}=8.306 \mathrm{~J} / \mathrm{mol} \quad \mathrm{K}$

The local solidification time is equal to $\left(T_{\mathrm{L}}-T_{\mathrm{S}}\right) / R_{\mathrm{C}}$ and the equilibrium distribution coefficients and diffusion coefficients of solutes in solid are given in Table 1 , where $R_{\mathrm{C}}$ is the cooling rate of steel. Then the segregation of solute elements in molten and solid steel during solidification can be calculated with the above equations.

\subsection{Inclusion Precipitation}

It is assumed that the oxides are uniformly dispersed in the specimen. In molten steel, due to the enrichment of solute elements during solidification, new non-metallic inclusions precipitate and grow when the solute elements exceed the equilibrium value.

The precipitation of inclusion, taking $\mathrm{MnS}$ as an example, starts immediately after the product of Mn and S contents in solution reaches the equilibrium solubility limit in each phase. Between inclusions and iron, these two phases are in equilibrium. That is, the following reactions reach equilibrium. ${ }^{4,10)}$

$$
\begin{aligned}
& \text { Liquid: } \\
& \underline{\mathrm{Mn}}+\underline{\mathrm{S}}=(\mathrm{MnS}) \quad \log K=8627 / T-4.745 \\
& \delta \text { phase: } \\
& \underline{\mathrm{Mn}}+\underline{\mathrm{S}}=(\mathrm{MnS}) \quad \log K=-10590 / T+4.302 \\
& -0.07[\% \mathrm{Si}] \\
& 2 \underline{\mathrm{Al}}+3 \underline{\mathrm{O}}=\left(\mathrm{Al}_{2} \mathrm{O}_{3}\right) \quad \log K=64000 / T-20.57 \\
& \underline{\mathrm{Si}}+2 \underline{\mathrm{O}}=\left(\mathrm{SiO}_{2}\right) \quad \log K=30110 / T-11.40 \\
& \underline{\mathrm{Mn}}+\underline{\mathrm{O}}=(\mathrm{MnO}) \quad \log K=11749 / T-4.666 \\
& 6 \underline{\mathrm{Al}}+2 \underline{\mathrm{Si}}+13 \underline{\mathrm{O}}=\left(3 \mathrm{Al}_{2} \mathrm{O}_{3} \cdot 2 \mathrm{SiO}_{2}\right) \\
& \log K=251394 / \mathrm{T}-83.135
\end{aligned}
$$

In the present model the calculation of inclusion precipitation is based on the material balance expressed at each instant for each solute element by the following relationship:

For Mn,

$$
\begin{aligned}
\sum_{i=1}^{N} C_{\mathrm{L}, \mathrm{Mn}}^{0}= & \sum_{i=1}^{m} C_{i, \mathrm{Mn}}^{t}+(N-m) \cdot C_{\mathrm{L}, \mathrm{Mn}}^{t} \\
& \times \sum_{i=1}^{m} \operatorname{Cin}_{i, \mathrm{Mn}}^{t} \cdot(N-i+1) \ldots .
\end{aligned}
$$

For $\mathrm{S}$,

$$
\sum_{i=1}^{N} C_{\mathrm{L}, \mathrm{S}}^{0}=\sum_{i=1}^{m} C_{i, \mathrm{~S}}^{t}+(N-m) \cdot C_{\mathrm{L}, \mathrm{S}}^{t} \sum_{i=1}^{m} \operatorname{Cin}_{i, \mathrm{~S}}^{t} \cdot(N-i+1)
$$

Table 2. Activity interaction parameters at $1873 \mathrm{~K} .{ }^{9,15)}$

\begin{tabular}{|c|c|c|c|c|c|c|c|}
\hline$e_{i}^{j}(\mathrm{j})$ & $\mathrm{C}$ & $\mathrm{Si}$ & $\mathrm{Mn}$ & $\mathrm{P}$ & $\mathrm{S}$ & $\mathrm{Al}$ & 0 \\
\hline $\mathrm{Si}$ & 0.18 & 0.103 & -0.0146 & 0.09 & 0.066 & 0.058 & -0.119 \\
\hline $\mathrm{Mn}$ & -0.0538 & -0.0327 & 0 & -0.06 & -0.048 & 0.027 & -0.087 \\
\hline $\mathrm{Al}$ & 0.091 & 0.056 & 0.035 & 0.033 & 0.035 & 0.043 & -1.98 \\
\hline 0 & -0.42 & -0.066 & -0.0224 & 0.07 & -0.133 & -1.17 & -0.17 \\
\hline $\mathrm{S}$ & 0.112 & 0.063 & -0.026 & 0.29 & -0.028 & 0.035 & -0.27 \\
\hline
\end{tabular}

Where Cin is the consumption of solute elements (for example, $\mathrm{Mn}$ or $\mathrm{S}$ ) due to inclusion precipitation from time $t-d t$ to time $t$ during solidification.

From time $t-d t$ to time $t$, nodal $i$ solidifies. During this period, the consumption of solute elements due to inclusion precipitation in nodal $i$ is assumed to be equal to that in the molten steel in the present model.

At the same time, in molten steel,

$$
\begin{gathered}
C_{\mathrm{L}, \mathrm{Mn}}^{t} \cdot f_{\mathrm{Mn}} \cdot C_{\mathrm{L}, \mathrm{S}}^{t} \cdot f_{\mathrm{S}}=K_{\mathrm{L}, \mathrm{MnS}} \\
\operatorname{Cin}_{i, \mathrm{~S}}^{t} \cdot M_{\mathrm{Mn}}=\operatorname{Cin}_{i . \mathrm{Mn}}^{t} \cdot M_{\mathrm{S}}
\end{gathered}
$$

Where $f_{\mathrm{S}}$ and $f_{\mathrm{Mn}}$ are the activity coefficients of $\mathrm{S}$ and $\mathrm{Mn}$ in molten steel respectively and can be calculated using Eq. (13). ${ }^{14)}$

$$
\log f_{i}=e_{i}^{i}[\% i]+\sum e_{i}^{j}[\% j]
$$

Based on E. T. Turkdogan's data, ${ }^{14)}$ Eq. (14) was induced to calculate the value of $f_{\mathrm{S}}^{\mathrm{Si}}$ for the mass concentration of silicon above $1 \%$.

$$
f_{\mathrm{S}}^{\mathrm{Si}}=0.3067[\% \mathrm{Si}]+0.72
$$

The data used in the thermodynamic calculation are listed in Table 2. ${ }^{9,15}$ )

Combining Eqs. (1)-(6) and (9)-(14), the concentration of each solute element and the amount of precipitated MnS can be calculated during solidification. The precipitation of oxides are treated just in the same manner as the precipitation of MnS from molten steel, and the concentration of oxygen in molten steel is assumed to be in equilibrium with the strong deoxidizer. That means, for example, when the reaction between $\mathrm{SiO}_{2}$ and $\mathrm{Al}_{2} \mathrm{O}_{3}$ occurs, mullite $\left(3 \mathrm{Al}_{2} \mathrm{O}_{3}\right.$. $2 \mathrm{SiO}_{2}$ ) precipitates and oxygen is in equilibrium with both $\mathrm{Al}$ and $\mathrm{Si}$ at the same time in molten steel. In that case, the concentration of oxygen in equilibrium with both $\mathrm{Al}$ and $\mathrm{Si}$ must be less than that in equilibrium with $\mathrm{Al}$ or Si respectively.

\subsection{Flow Chart of the Present Model}

The flow chart of the present model is shown in Fig. 3. Both precipitation of oxides and sulfides from molten steel are taken into account in the present model.

\section{Results and Discussion}

\subsection{The Precipitation of Inclusions during Solidifica- tion}

The steel which was studied by M. Wintz et al. ${ }^{16)}$ is taken as an example for the application of the above model, which has a composition of $1.00 \% \mathrm{C}, 1.50 \% \mathrm{Cr}, 0.36 \%$ $\mathrm{Mn}, 0.27 \% \mathrm{Si}, 0.018 \% \mathrm{~S}$ and $0.019 \% \mathrm{P}$ in mass\%. Figure 4 shows a good consistency of manganese content in inter- 


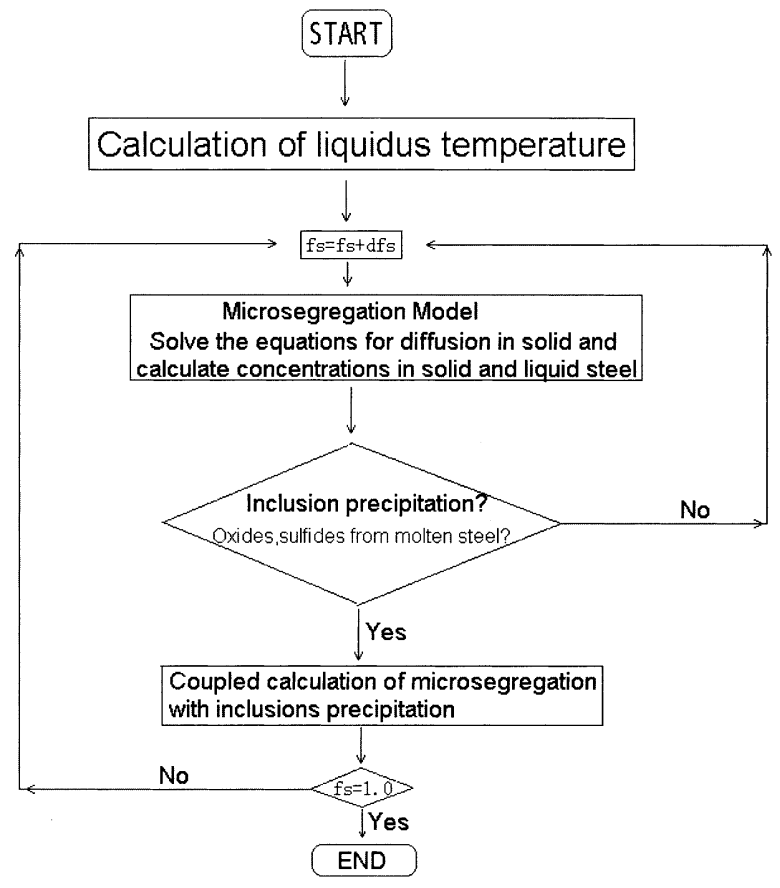

Fig. 3. Flow chart for the calculation of solute distribution and inclusion precipitation.

dendritic liquid during solidification between computed by the present model and measured by M. Wintz et al. It is shown that the manganese content decrease after the sulfides begin to precipitate, which means that the amount of manganese consumption for sulfides precipitation is larger than the amount of manganese rejected from the solidifying metal.

Without considering the effect of oxides on the precipitation of sulfides, the precipitation of oxides and sulfides of studied steel is shown in Fig. 5. Figure 5 shows that mullite starts to precipitate at the beginning of the solidification and sulfide precipitate at the end of the solidification of studied steel.

$\mathrm{Z} . \mathrm{Ma}^{9)}$ calculated the growth of oxides during solidification using Eq. (15), which is based on the following oxygen mass balance in a volume element at any time.

The initial total oxygen content in molten steel=the sum of oxygen content in oxides which exist in solid steel + the remaining amount of oxygen in molten steel + the amount of oxygen contained in the oxides presented in molten steel

$$
\begin{aligned}
& \frac{4}{3} \pi r_{0}^{3} \rho_{\mathrm{s}}^{0} W_{\mathrm{O}}^{0}+\left(1-\frac{4}{3} \pi r_{0}^{3} N\right)[\% \mathrm{O}]^{0} \rho_{\mathrm{m}} \\
& =\sum_{t=0}^{t=t}\left(f_{\mathrm{s}}^{t+\Delta t}-f_{\mathrm{s}}^{t}\right) \frac{4}{3} \pi r_{t}^{3} N \rho_{\mathrm{s}}^{t} W_{\mathrm{O}}^{t} \\
& \quad+\left(1-f_{\mathrm{s}}^{t+\Delta t}-\frac{4}{3} \pi r_{t}^{3} N\left(1-f_{\mathrm{s}}^{t+\Delta t}\right)\right) \times[\% \mathrm{O}]^{t+\Delta t} \rho_{\mathrm{m}} \\
& \quad+\frac{4}{3} \pi r_{t+\Delta t}^{3} N\left(1-f_{\mathrm{s}}^{t+\Delta t}\right) \rho_{\mathrm{s}}^{t+\Delta t} W_{\mathrm{O}}^{t+\Delta t} \ldots \ldots \ldots \ldots \ldots \ldots . . . . . . . . .1
\end{aligned}
$$

Where $r_{0}$ and $r_{t}$ represent the initial radius and radius of oxide during solidification respectively, $\rho_{\mathrm{s}}$ and $\rho_{\mathrm{m}}$ represent

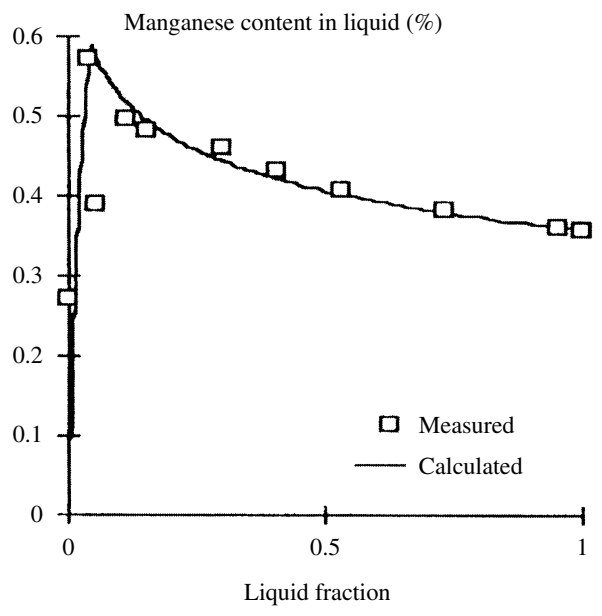

(a)

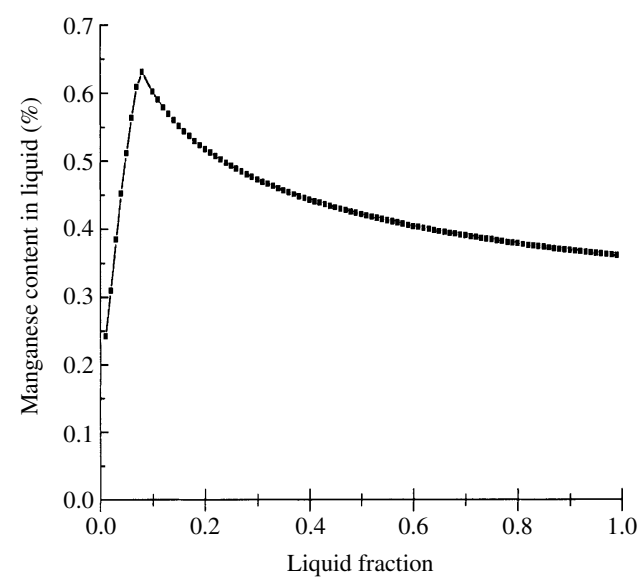

(b)

Fig. 4. Manganese content in interdendritic liquid versus liquid fraction.

(a): measured by M. Wintz et al., (b): calculated by the present model

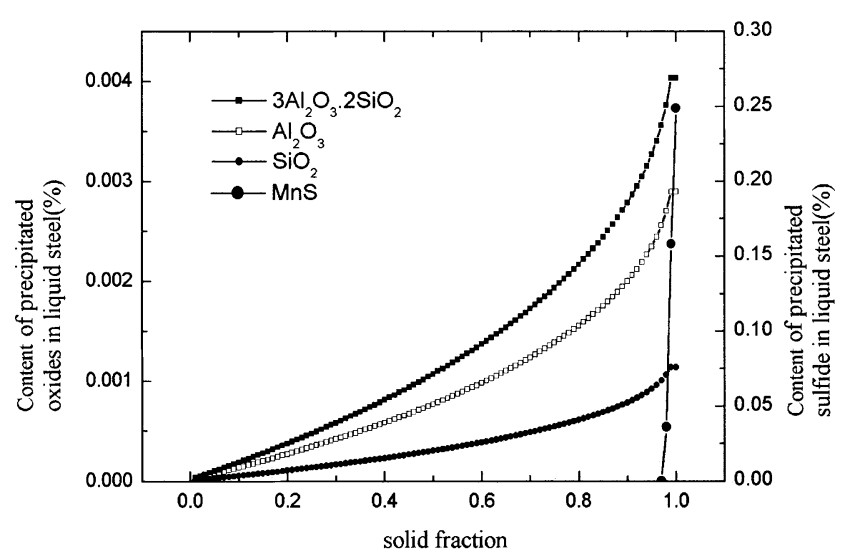

Fig. 5. Precipitation of oxides and sulfides in silicon steel during solidification.

the density of oxides and molten steel respectively, $N$ is the number of the oxides per unit volume (number $\left./ \mathrm{cm}^{3}\right), W_{\mathrm{O}}^{0}$ and $W_{\mathrm{O}}^{t}$ represent the initial mass percentage of oxygen in oxides and that during solidification respectively.

But Z. Ma omitted the amount of oxygen in solid steel. 


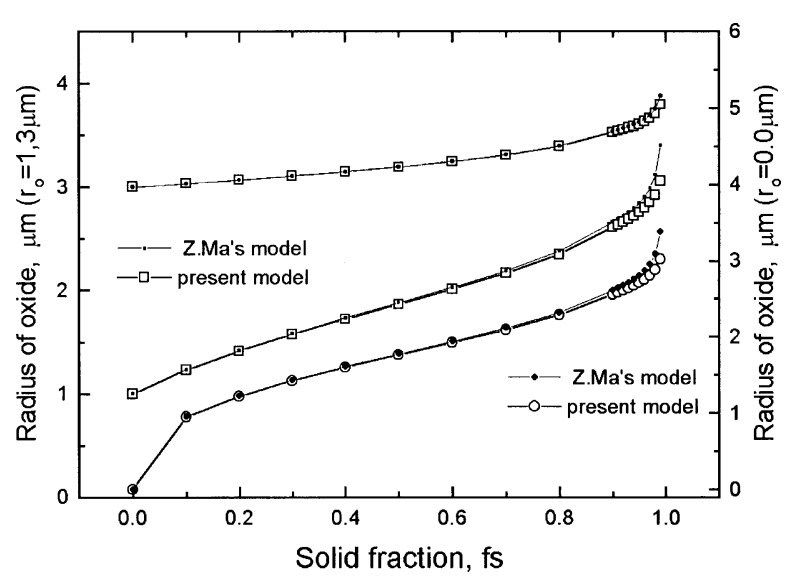

Fig. 6. Comparison the growth calculated with Z. Ma's model and the present model during solidification.

In the present paper, the equation of $\mathrm{Z}$. Ma is modified by taking into account of the amount of oxygen in solid steel. The growth of oxides calculated with $Z$. Ma's model and the present model is shown in Fig. 6. It is clear that value calculated with the present model is less than that with $\mathrm{Z}$. Ma's model and is more suited to the actual situation.

\subsection{Effect of Inclusion Precipitation on the Micro- segregation of Solute Elememts}

The microsegregation ratio $\left(R C_{l} / C_{0}\right)$ of $\mathrm{Al}, \mathrm{Si}$ and $\mathrm{O}$ during solidification calculated with the present coupled model and non-coupled model are compared in Fig. 7. It is clearly shown that the microsegregation of $\mathrm{Al}$ and $\mathrm{O}$ is greatly suppressed due to the oxide precipitation. At the end of solidification, the value of $R$ for $\mathrm{Al}$ is 1.5 and 2.1, calculated by coupled and non-coupled model respectively. For O, 1.0 and 33 respectively.

Because the concentration of $\mathrm{Si}$ in studied steel is very high and the equilibrium distribution coefficient of $\mathrm{Si}\left(k_{\mathrm{Si}}\right)$ is small, the difference of microsegregation ratio between calculated with two models is small. It is also clear that the non-coupled model will overestimate the segregation degree and the amount of inclusion precipitation and even give a wrong prediction on the kind of the inclusions.

\subsection{Effect of Cooling Rates on the Precipitation and Growth of Inclusion during Solidification}

The effect of cooling rates on the precipitation and growth of inclusion during solidification is shown in Fig. 8. According to T. Emi's ${ }^{17)}$ and H. Goto's ${ }^{18)}$ report, the oxides inclusion number is about $10^{8}$ per $\mathrm{cm}^{3}$ in clean steel and the number of oxides increases with the increasing cooling rate. Thus, the inclusion number is assumed to be $10^{7} \mathrm{~cm}^{-3}$, $10^{8} \mathrm{~cm}^{-3}$ and $10^{9} \mathrm{~cm}^{-3}$ corresponding to cooling rate of 10 $\mathrm{K} / \mathrm{min}, 100 \mathrm{~K} / \mathrm{min}$ and $500 \mathrm{~K} / \mathrm{min}$ respectively.

It is clearly shown that the radius of oxides is greatly affected by the cooling rate. At a low cooling rate of $10 \mathrm{~K} / \mathrm{min}$, the oxides, with initial radius of $0 \mu \mathrm{m}, 1 \mu \mathrm{m}$, $3 \mu \mathrm{m}$ and $5 \mu \mathrm{m}$, will reach $6.51 \mu \mathrm{m}, 6.63 \mu \mathrm{m}, 6.72 \mu \mathrm{m}$ and $7.38 \mu \mathrm{m}$ respectively at the end of solidification. While at a high cooling rate of $500 \mathrm{~K} / \mathrm{min}$, the change of oxides radius is small, especially for oxides with initial radius of $3 \mu \mathrm{m}$ and $5 \mu \mathrm{m}$. For silicon steel, adopting a low cooling rate will

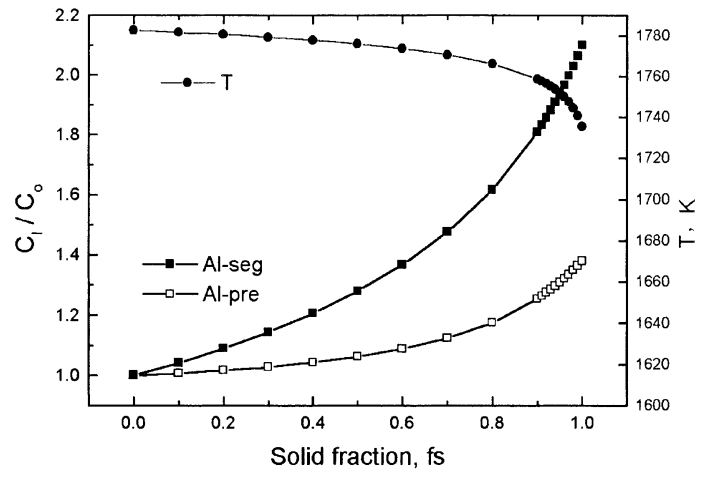

(a)

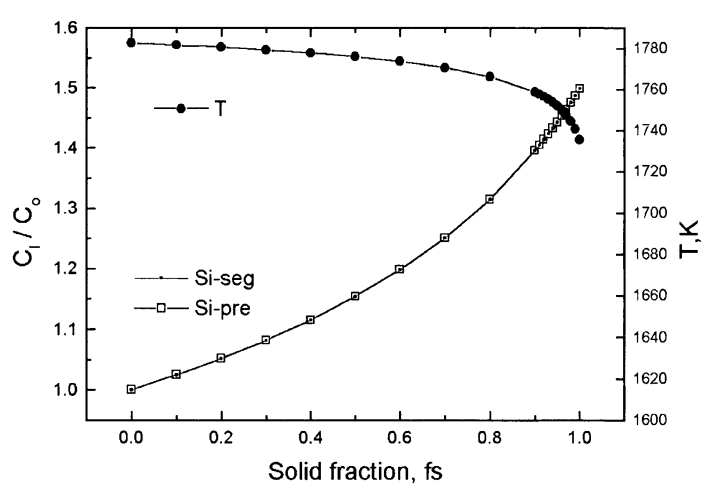

(b)

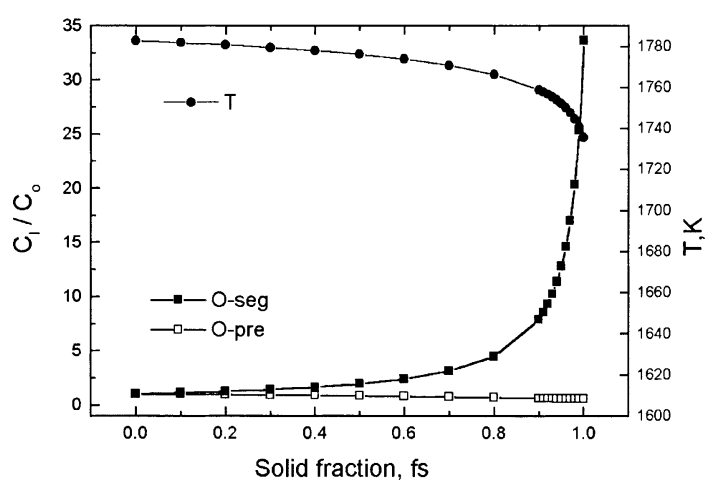

(c)

Fig. 7. The degree of microsegregation of solute elements during solidification, where Al-seg, Si-seg, O-seg: calculated with non-coupled model; Al-pre, Si-pre, O-pre: calculated with the present coupled model.

reduce the number of inclusion nucleus and promote the inclusion growth, which is helpful to improve the magnetic properties.

\section{Conclusions}

A mathematical model for the solidification of silicon steel is presented. In the model the calculation of microsegregation of solute elements is coupled with the precipitation of inclusions, and the precipitation of oxides and sulfides can be calculated simultaneously.

The calculation by the present model shows that the segregation degree of solute elements is suppressed greatly due to the precipitation of inclusions during solidification. For 


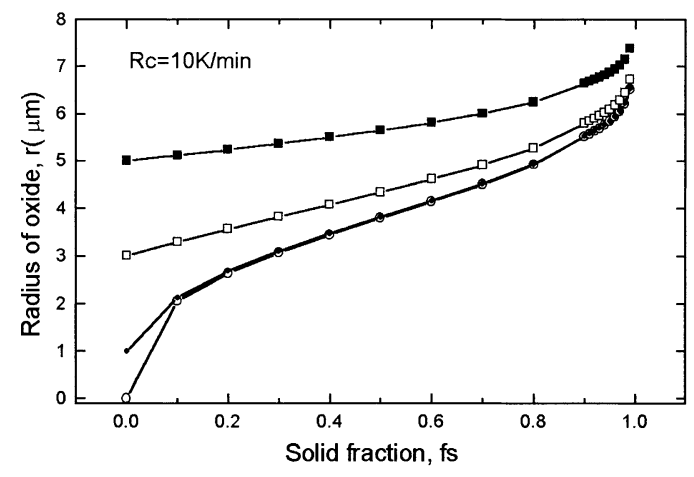

(a)

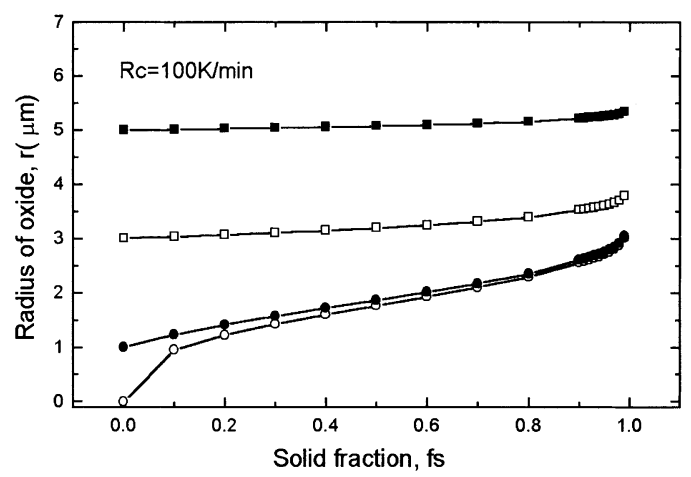

(b)

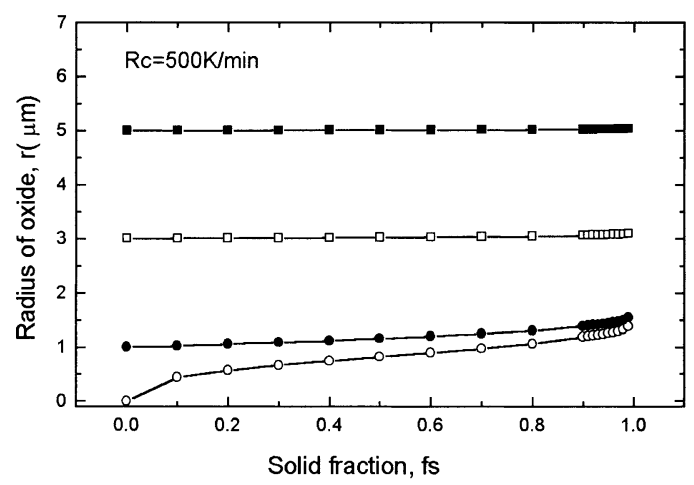

(c)

Fig. 8. Calculated radius of oxides during solidification of silicon steel at three different cooling rates.

silicon steel, the segregation ratio for Al calculated with coupled and non-coupled model is 1.5 and 2.1 respectively. For oxygen, 1.0 and 33 respectively. A non-coupled model may overestimate the segregation degree and the amount of inclusion precipitation and even give a wrong prediction on the kind of the inclusions.

For the studied silicon steel, the precipitate is mullite. But $\mathrm{MnO}$ can not precipitate due to high concentration of silicon in steel. The precipitation and growth of oxides are greatly affected by the cooling rate. A low cooling rate is helpful to reduce inclusion number, promote inclusion growth and improve magnetic properties of silicon steel.

\section{Acknowledgements}

The authors wish to express their thanks to the members of the Institute of Steelmaking, Metallurgical Engineering School, University of Science and Technology Beijing, for support of this work. Special thanks are due to Prof. Jiaquan Zhang and Prof. Junpu Jiang.

\section{REFERENCES}

1) E. Forster and H. Richter: Proc. of Production and Application of Clean Steels, Hungary, Iron and Steel Institute, London, (1970), 24.

2) E. Grethen and L. Philippe: Proc. of Production and Application of Clean Steels, Hungary, Iron and Steel Institute, London, (1970), 29.

3) A. Kohn, M. Wanin, J. Arnoult, R. Thomas and L. Backer: Proc. of Production and Application of Clean Steels, Hungary, Iron and Steel Institute, London, (1970), 92.

4) J. Takamura and S. Mizoguchi: Proc. 6th Int. Iron and Steel Cong., Vol. I, ISIJ, Tokyo, (1990), 591.

5) S. Mizoguchi and J. Takamura: Proc. 6th Int. Iron and Steel Cong., Vol. I, ISIJ, Tokyo, (1990), 598.

6) S. Ogibayashi, K. Yamaguchi, M. Hirai, H. Goto, H. Yamaguchi and K. Tanaka: Proc. 6th Int. Iron and Steel Cong., Vol. I, ISIJ, Tokyo, (1990), 612.

7) W. Yamada and T. Matsumiya: Proc. 6th Int. Iron and Steel Cong., Vol. I, ISIJ, Tokyo, (1990), 618.

8) D. Lou, K. Cui, X. Wu and J. Zhang: Acta Metall. Sin., 32 (1996), 1027.

9) Z. Ma and D. Janke: ISIJ Int., 38 (1998), 46.

10) Y. Ueshima, K. Isobe, S. Mizoguchi H. Maede and H. Kajioka: Tetsu-to-Hagané, 74 (1988), 465.

11) Y. Ueshima, Y. Sawada, S. Mizoguchi and H. Kajioka: Metall. Trans. $A, 20 A$ (1989), 1375.

12) Y. Ueshima, S. Mizoguchi, T. Matsumiya and H. Kajioka: Metall. Trans. B, 17B (1986), 845.

13) M. M. Wolf and W. Kurz: Metall. Trans. B, 12B (1981), 85.

14) E. T. Turkdogan: Fundamentals of Steelmaking, The Institute of Materials, Cambridge, (1996), 94.

15) Y. Qu: Principe of Steelmaking, Metallurgical Industry Press, Beijing, (1991), 182.

16) M. Wintz, M. Bobadilla and J. Lehmann: IRSID-RE 97.002.1, (1997).

17) T. Emi: Scand. J. Metall., 4 (1975), 1.

18) H. Goto, K. Miyazawa, K. Yamaguchi, S. Ogibayashi and K. Tanaka: ISIJ Int., 34 (1994), 414. 